\title{
A Fragmentation Study on Four Unusual Secoiridoid Trimers, Swerilactones H-K, by Electrospray Tandem Mass Spectrometry
}

\author{
Chang-An Geng · Ji-Jun Chen
}

Received: 14 October 2016/Accepted: 6 November 2016/Published online: 14 November 2016

(C) The Author(s) 2016. This article is published with open access at Springerlink.com

\begin{abstract}
Swerilactones H-K (1-4) as four unprecedented secoiridoid trimers represent a new type of natural product, which has attracted much interest of natural chemists due to their novel skeletons and promising bioactivity. In order to well understand their MS fragmentation behaviors, they were investigated by electrospray ionization ion-trap time-of-flight multistage product ion mass spectrometry $\left(\right.$ ESI-IT-TOF-MS $\left.{ }^{n}\right)$ for the first time. The protonated molecules $\left([\mathrm{M}+\mathrm{H}]^{+}\right)$of swerilactones $\mathrm{J}$ and $\mathrm{K}$, and deprotonated molecules $\left([\mathrm{M}-\mathrm{H}]^{-}\right.$) of swerilactones $\mathrm{H}, \mathrm{J}$ and $\mathrm{K}$ were readily observed in the conventional single-stage mass spectra (MS); however only the $[\mathrm{M}+\mathrm{Cl}]^{-}$ion for swerilactone I was obtained in negative mode. Based on the $\mathrm{MS}^{n}$ study, the fragmentation pathways of swerilactones $\mathrm{H}$ and $\mathrm{I}$ in negative mode, and swerilactones $\mathrm{J}$ and $\mathrm{K}$ in both positive and negative modes were proposed. The neutral losses of $\mathrm{H} 2 \mathrm{O}, \mathrm{CO}, \mathrm{CO}_{2}$ and $\mathrm{C}_{2} \mathrm{H}_{4} \mathrm{O}$ moieties are the particular elimination from the precursor ions due to the presence of hydroxyl, $\delta$-lactone and 1- $O$-ethyl moieties in their structures, of which the retro-Diels-Alder cleavage was the most particular dissociation. The fragment ions at $m / z, 341$ and 291 in negative mode can be considered as the diagnostic ions for secoiridoid trimers. This investigation will provide valuable information for their fast characterization from complicated natural mixtures and extensive understanding their structural architectures.
\end{abstract}

Keywords ESI-IT-TOF-MS ${ }^{n} \cdot$ Fragmentation rules $\cdot$ Secoiridoid trimers $\cdot$ Swerilactones H-K $\cdot$ Retro-Diels-Alder (RDA) cleavage

\section{Introduction}

Natural products with diversities in chemical structures and pharmacological activities provide versatile candidates in

Electronic supplementary material The online version of this article (doi:10.1007/s13659-016-0114-6) contains supplementary material, which is available to authorized users.

\section{C.-A. Geng - J.-J. Chen $(\bowtie)$}

State Key Laboratory of Phytochemistry and Plant Resources in West China, Kunming Institute of Botany, Chinese Academy of Sciences, No. 132 Lanhei Road, Kunming 650201, China e-mail: chenjj@mail.kib.ac.cn

C.-A. Geng · J.-J. Chen

Yunnan Key Laboratory of Natural Medicinal Chemistry, Kunming 650201, China drug discovery. Many natural chemists are committed to searching for novel compounds to enrich this library. Swerilactones H-K (1-4) (Fig. 1), unprecedented secoiridoid trimers from the traditional Chinese herb Swertia mileensis, represent a new type of natural product, which has attracted much interest of natural chemists due to their novel skeletons and promising bioactivity [1-2]. However, this type of compound exists as minor components in plants, which presents challenges for their fast and reliable characterization [3]. Mass spectrometry (MS) with the associated high sensitivity and resolution well meets this requirement and has become the routine method in various aspects of medicinal chemistry [4-8]. Tandem MS techniques are particularly useful for ascertaining the relationship between precursor and product ions, by which the fragmentation rules and diagnostic ions of complicated 


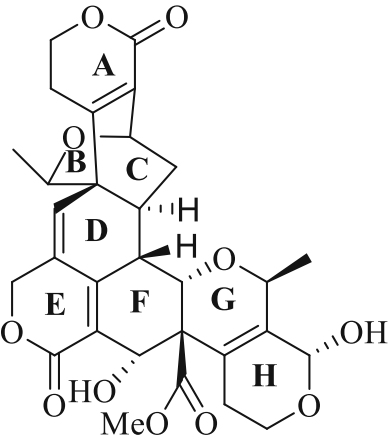

swerilactone H (1)

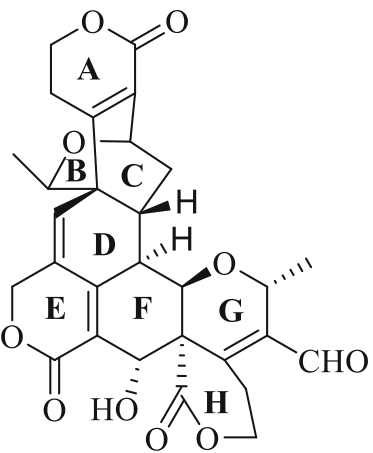

swerilactone I (2)

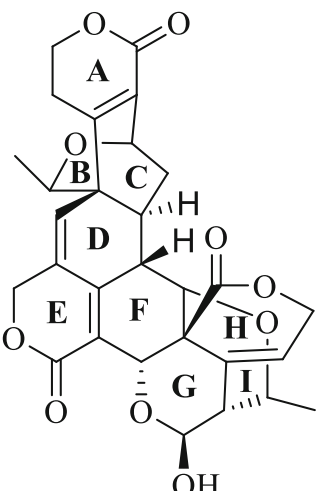

swerilactone J (3)

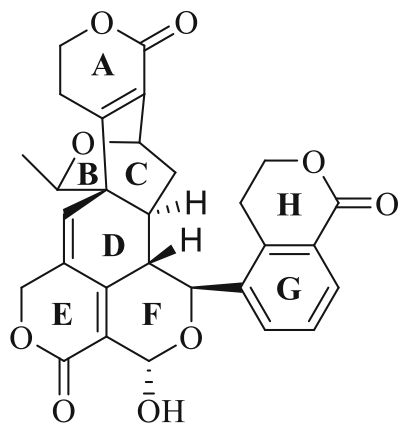

swerilactone K (4)

Fig. 1 Structures of compounds 1-4

compounds can be easily deduced [9-14]. The LCMS-ITTOF mass spectrometer equipped with an electrospray ionization source linked to ion-trap and time-of-flight mass analyzers (ESI-IT-TOF) allows fast acquisition of multistage product ion spectra $\left(\mathrm{MS}^{n}\right)$ with high accuracy and resolution in both positive and negative modes [15-17]. This feature leads to easier interpretation of the origin of product ions, which is suitable for investigating the structures of natural products. In this paper, we report for the first time a high-resolution $\mathrm{MS}^{n}$ fragmentation study on swerilactones H-K (1-4) by ESI-IT-TOF mass spectrometer, which will provide valuable information not only for their fast characterization from complicated natural mixtures but also for a better understanding of their structural architectures.

\section{Experimental}

\subsection{Apparatus and Analytical Conditions}

$\mathrm{MS}^{n}$ analyses were acquired on the LCMS-IT-TOF mass spectrometer (Shimadzu, Kyoto, Japan). The mass resolution was about 10000 full width at half maximum (FWHM). Accurate masses were corrected by calibration using sodium trifloroacetate $\left(\mathrm{CF}_{3} \mathrm{CO}_{2} \mathrm{Na}\right)$ clusters. MS experiments were achieved in automatic pattern, and $\mathrm{MS}^{n}$ experiments were performed in direct mode. Unless specified otherwise, analytical conditions were as follows: spray voltage, 4.50 and $-3.50 \mathrm{kV}$; detector voltage, $1.60 \mathrm{kV}$; drying gas pressure, $100.0 \mathrm{kPa}$; nebulizing gas $\left(\mathrm{N}_{2}\right)$ flow, $0.5 \mathrm{~L} / \mathrm{min}$; curved desolvation line (CDL) temperature, $200.0{ }^{\circ} \mathrm{C}$; heat block temperature, $200.0{ }^{\circ} \mathrm{C}$; equipment temperature, $40.0{ }^{\circ} \mathrm{C}$; ion accumulation time, $10 \mathrm{~ms}$; precursor ion selected width, $\mathrm{m} / \mathrm{z} \pm 3.0 \mathrm{Da}$, and selected time, $20 \mathrm{~ms}$; collision induced dissociation (CID) collision time, $30 \mathrm{~ms}$; collision energy, 50\%; collision gas, $50 \%$; and $\mathrm{q}=0.251$; scan range, $m / z, 100-1000$ for MS.
The Shimadzu Composition Formula Predictor was used to determine the molecular formula.

\subsection{Chemicals and Samples}

HPLC grade acetonitrile $\left(\mathrm{CH}_{3} \mathrm{CN}\right)$ was purchased from Merck (Merck Co. Ltd., Germany). HPLC grade formic acid was purchased from Aladdin (Aladdin Chemistry Co. Ltd. China). Deionized water was purified using a Min$\mathrm{gChe}^{\mathrm{TM}}$-D 24UV Merck Millipore system (Merck Millipore, Shanghai, China).

Swerilactones H-K (1-4) were isolated from $S$. mileensis in our previous investigation, whose structures were unambiguously determined by extensive spectroscopic data and X-ray analyses [1]. Sample solutions were prepared by dissolving each sample in a solution of $85 \%$ $\mathrm{CH}_{3} \mathrm{CN} / \mathrm{H}_{2} \mathrm{O}$ containing $0.05 \%$ formic acid to a final concentration of $0.2 \mathrm{mg} / \mathrm{mL}$. The samples were introduced into the source via a syringe pump at a flow rate of $2 \mu \mathrm{L} /$ min.

\section{Results and Discussion}

Before $\mathrm{MS}^{n}$ investigation, the full-scan MS of compounds 1-4 in both positive and negative ion modes were acquired in automatic pattern. The protonated molecule $\left([\mathrm{M}+\mathrm{H}]^{+}\right)$ and deprotonated molecule $\left([\mathrm{M}-\mathrm{H}]^{-}\right)$ions for swerilactones $\mathrm{J}(\mathbf{3})$ and $\mathrm{K}(\mathbf{4})$ were readily detected. However, swerilactones $\mathrm{H}(\mathbf{1})$ and I (2) only displayed $[\mathrm{M}-\mathrm{H}]^{-}$or $[\mathrm{M}+\mathrm{Cl}]^{-}$ion in negative mode. Therefore, the subsequent $\mathrm{MS}^{n}$ study for swerilactones $\mathrm{H}$ and I (1 and 2) in negative mode, and for swerilactones $\mathrm{J}$ and $\mathrm{K}$ (3 and $\mathbf{4})$ in both positive and negative modes was performed, from which their fragmentation pathways were proposed (Figs. 2, 3, 4, 5). It should be noted that alternative ways of fragmentation that can reasonably interpret the product ions are also possible in addition to the proposed pathway. 


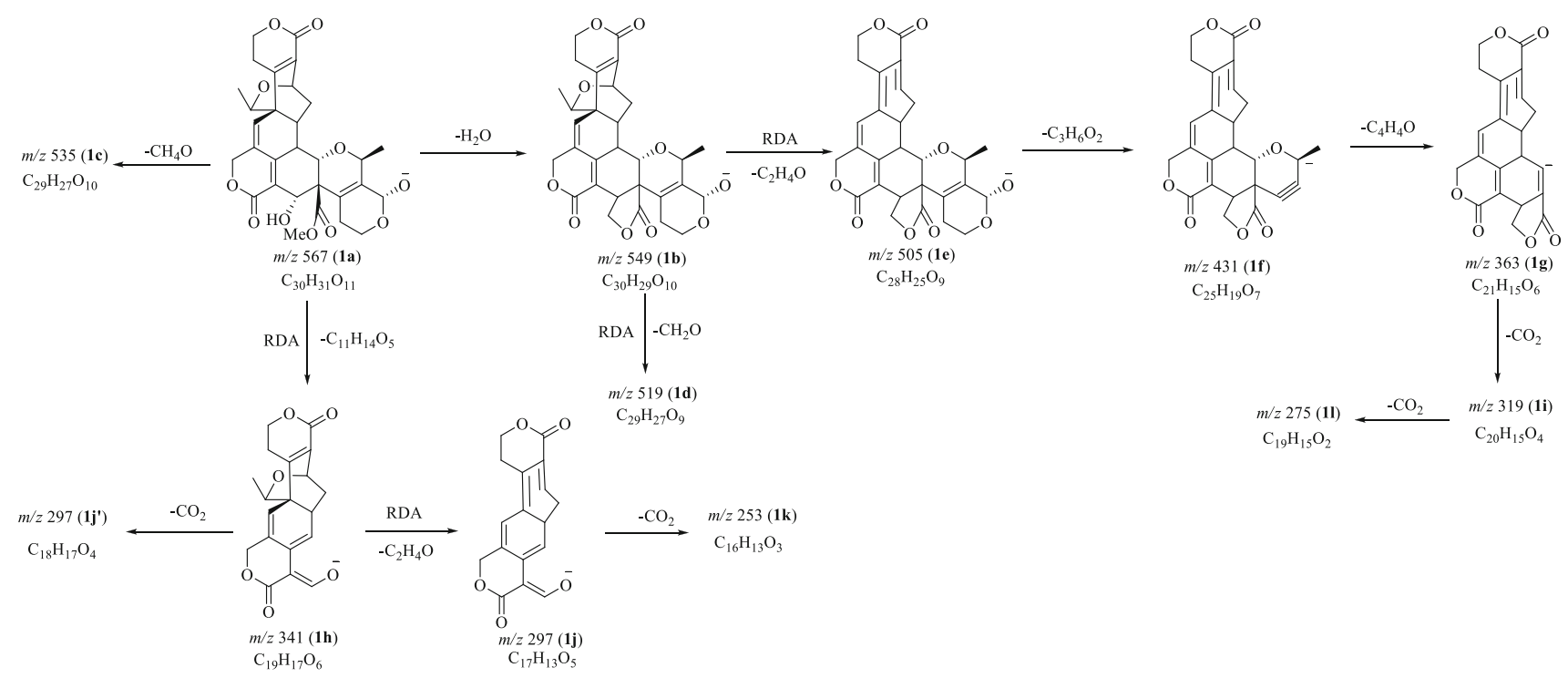

Fig. 2 Proposed fragmentation pathways of swerilactone $H(\mathbf{1})$ in negative mode
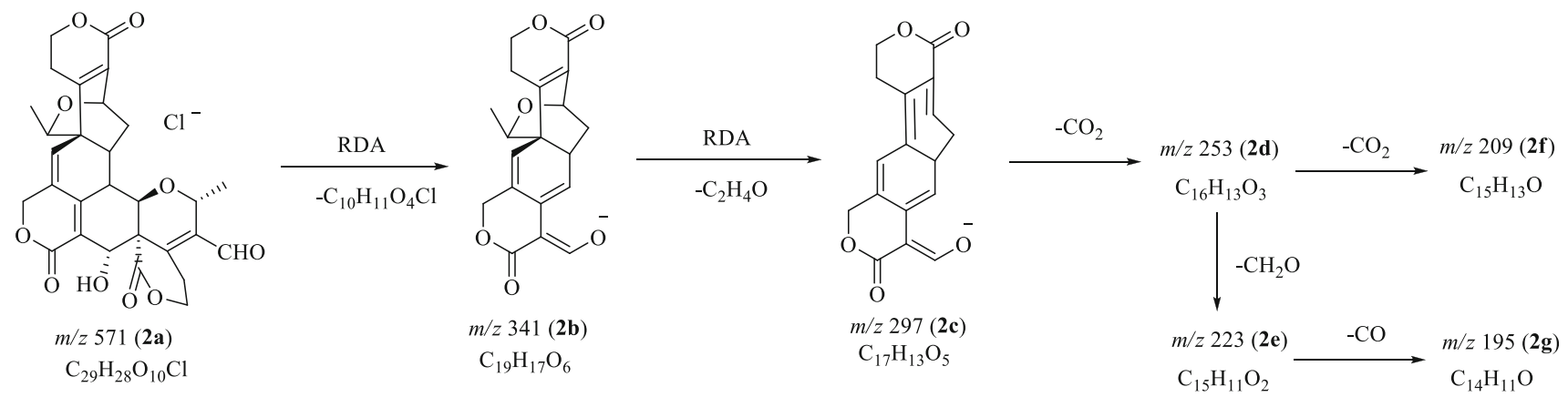

Fig. 3 Proposed fragmentation pathways of swerilactone I (2) in negative mode

\subsection{ESI-IT-TOF MS ${ }^{n}$ Fragmentations of Swerilactone $\mathrm{H}$ (1) in Negative Mode}

In the single-stage mass spectrum of swerilactone $\mathrm{H}(\mathbf{1})$, the deprotonated molecular $[\mathrm{M}-\mathrm{H}]^{-}$ion at $\mathrm{m} / \mathrm{z} 567.1871$ (1a) was readily obtained, corresponding to the molecular formula $\mathrm{C}_{30} \mathrm{H}_{32} \mathrm{O}_{11}$. When $[\mathrm{M}-\mathrm{H}]^{-}$(1a) was selected as the precursor ion to perform $\mathrm{MS}^{2}$ experiment, multiple product ions (1)-1k) were observed. Among them, the ions at $\mathrm{m} / \mathrm{z} 549$ (1b) and 535 (1c) were deduced to be generated by the neutral losses of $\mathrm{H}_{2} \mathrm{O}$ and $\mathrm{CH}_{4} \mathrm{O}$ from $\mathbf{1 a}$ due to the presence of vicinal hydroxyl and methoxy groups [18-19]. The product ions at $m / z, 519$ (1d) and 505 (1e) were assigned to be the elimination of $\mathrm{CH}_{2} \mathrm{O}$ and the retroDiels-Alder (RDA) cleavage of $\mathrm{C}_{2} \mathrm{H}_{4} \mathrm{O}$ from 1b [20]. Similarly, the cleavage of ring $\mathrm{H}$ by losing one $\mathrm{C}_{3} \mathrm{H}_{6} \mathrm{O}_{2}$ fragment from 1e generated ion $1 \mathbf{f}$ at $\mathrm{m} / \mathrm{z}$ 431, and the most abundant ion at $\mathrm{m} / \mathrm{z} 363(\mathbf{1 g})$ could be explained by subsequent loss of a $\mathrm{C}_{4} \mathrm{H}_{4} \mathrm{O}$ molecule by an RDA-like process [21]. It is noteworthy that two abundant ions at $\mathrm{m} / \mathrm{z}, 341$ (1h) and $297\left(\mathbf{1 j} / \mathbf{1} \mathbf{j}^{\prime}\right)$ were readily observed in the $\mathrm{MS}^{2}$ spectrum, of which the ions at $\mathrm{m} / \mathrm{z} 297$ were present as double peaks at $m / z 297.0792(\mathbf{1 j})$ and $297.1105\left(\mathbf{1 j}^{\prime}\right)$, corresponding to the chemical composition of $\mathrm{C}_{17} \mathrm{H}_{13} \mathrm{O}_{5}$ and $\mathrm{C}_{18} \mathrm{H}_{17} \mathrm{O}_{4}$ (Fig. 2). The ion at $\mathrm{m} / z 341$ (1h) could be well interpreted by the RDA cleavage of ring $\mathrm{F}$ to lose a $\mathrm{C}_{11} \mathrm{H}_{14} \mathrm{O}_{5}$ part [22-23]. Thus, the elimination of $44 \mathrm{Da}$ can be attributed to the losses of $\mathrm{C}_{2} \mathrm{H}_{4} \mathrm{O}$ and $\mathrm{CO}_{2}$ to yield product ions $\mathbf{1 j}(\mathrm{m} / \mathrm{z} 297.0792)$ and $\mathbf{1 j} \mathbf{j}^{\prime}(\mathrm{m} / \mathrm{z}$ 297.1105) [24]. Likewise, the ion $\mathbf{1 j}$ could further lose a molecule of $\mathrm{CO}_{2}$ to generate ion $1 \mathbf{k}(\mathrm{m} / \mathrm{z} 253)$. In the $\mathrm{MS}^{3}$ experiment from the precursor ion $\mathbf{1 g}(\mathrm{m} / \mathrm{z}, 363)$, two product ions at $\mathrm{m} / \mathrm{z}, 319$ (1i) as base peak and 275 (11) were detected, which were proposed to be arisen from the sequential loss of two $\mathrm{CO}_{2}$ molecules.

\subsection{ESI-IT-TOF MS ${ }^{n}$ Fragmentations of Swerilactone I (2) in Negative Mode}

Compared to swerilactones $\mathrm{H}, \mathrm{J}$ and $\mathrm{K}$, swerilactone I (2) was more unstable in this $\mathrm{MS}^{n}$ study, and thus, gave rise to less $\mathrm{MS}^{n}$ information, which might be due to the presence 


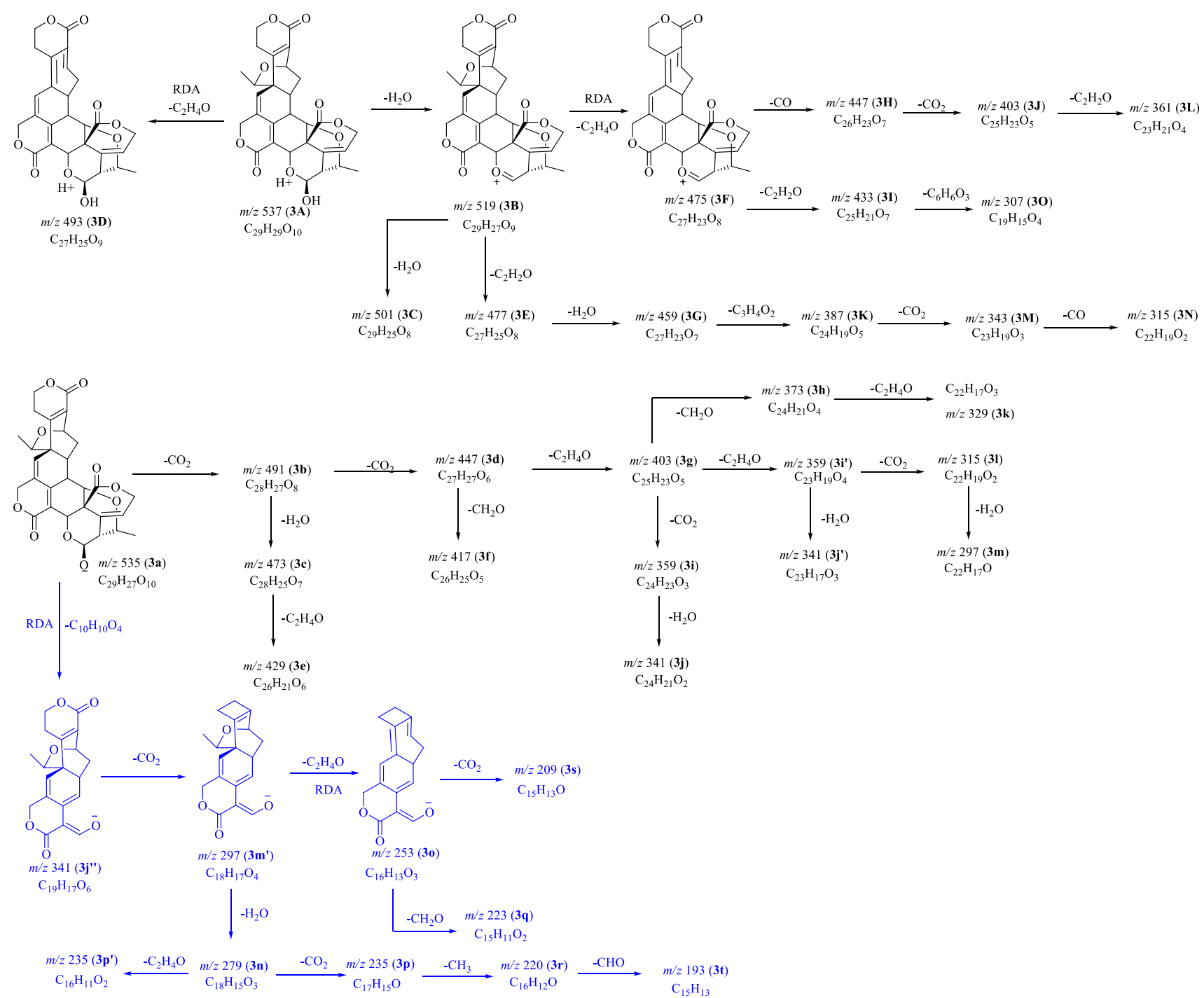

Fig. 4 Proposed fragmentation pathways of swerilactone $\mathbf{J}(\mathbf{3})$ in positive and negative modes

of aldehyde group in the structure. In the full-scan mass spectrum, swrilactone I (2) displayed neither $[\mathrm{M}+\mathrm{H}]^{+}$nor $[\mathrm{M}-\mathrm{H}]^{-}$ions, but an ion at $\mathrm{m} / \mathrm{z} 571.1383$ (2a) was readily obtained in the negative ion mode. This ion was ascribed with the chemical composition of $\mathrm{C}_{29} \mathrm{H}_{28} \mathrm{O}_{10} \mathrm{Cl}\left([\mathrm{M}+\mathrm{Cl}]^{-}\right)$ based on its high accordance in both accuracy $(0.7 \mathrm{mDa})$ and isotopic abundance $(83.9 \%)$ with those of the theoretical values. However, the origin of $\mathrm{Cl}^{-}$ion was unclear, which was always encountered in negative ESIMS investigation [25-26]. In addition to the $[\mathrm{M}+\mathrm{Cl}]^{-}$ion, two fragments at $\mathrm{m} / \mathrm{z} 341$ (2b) and 297 (2c) were observed with high abundance. The ion $\mathbf{2} \mathbf{b}$ corresponding to the loss of a $\mathrm{C}_{10} \mathrm{H}_{11} \mathrm{O}_{4} \mathrm{Cl}$ motif (rings $\mathrm{G}$ and $\mathrm{H}$ ) from ion $2 \mathrm{a}$ could be explained by the RDA ring-opening of ring $\mathrm{F}$, and the ion 2c was proposed to be generated by a further RDA process leading to the loss of a $\mathrm{C}_{2} \mathrm{H}_{4} \mathrm{O}$ part from ion $2 \mathbf{b}$ (Fig. 3). The above deduction was confirmed by the $\mathrm{MS}^{2}$ experiment on $\mathbf{2 a}$, which gave rise to the expected ions $\mathbf{2 b}$ $(\mathrm{m} / \mathrm{z}, 341)$ and $2 \mathbf{c}(\mathrm{m} / \mathrm{z} 297)$, and the subsequent $\mathbf{M S}^{3}$ experiment on $\mathbf{2 b}$ in which the fragment ion at $\mathrm{m} / \mathrm{z} 297$ (2c) was further detected. Combined with the observation that the fragmentation ion 2c showed much higher abundance compared to the parent $[\mathrm{M}+\mathrm{Cl}]^{-}$ion in the first stage mass spectrum, the following $\mathrm{MS}^{2}$ experiment was further performed on ion $\mathbf{2 c}(\mathrm{m} / \mathrm{z} 297)$ to generate three characteristic ions at $\mathrm{m} / z 253$ (2d), 223 (2e) and 209 (2f). The ion 2d was attributed to the neutral loss of a $\mathrm{CO}_{2}$ moiety from ion $\mathbf{2 c}$, and the ions $2 \mathbf{e}$ and $\mathbf{2 f}$ were corresponding to the elimination of one $\mathrm{CH}_{2} \mathrm{O}$ or $\mathrm{CO}_{2}$ parts from $2 \mathrm{~d}$. In the $\mathrm{MS}^{3}$ experiment on ion $\mathbf{2 d}$, the expected fragment ions $\mathbf{2 e}(\mathrm{m} / \mathrm{z}$ $223)$ and $\mathbf{2 f}(\mathrm{m} / z 209)$ were readily displayed, which was in accordance with the above deduction. When ion $2 \mathbf{e}$ was further selected for $\mathrm{MS}^{4}$ experiment, a fragment ion at $\mathrm{m} / \mathrm{z}$ 195 (2g) corresponding to a $28 \mathrm{Da}$ loss was obtained, 


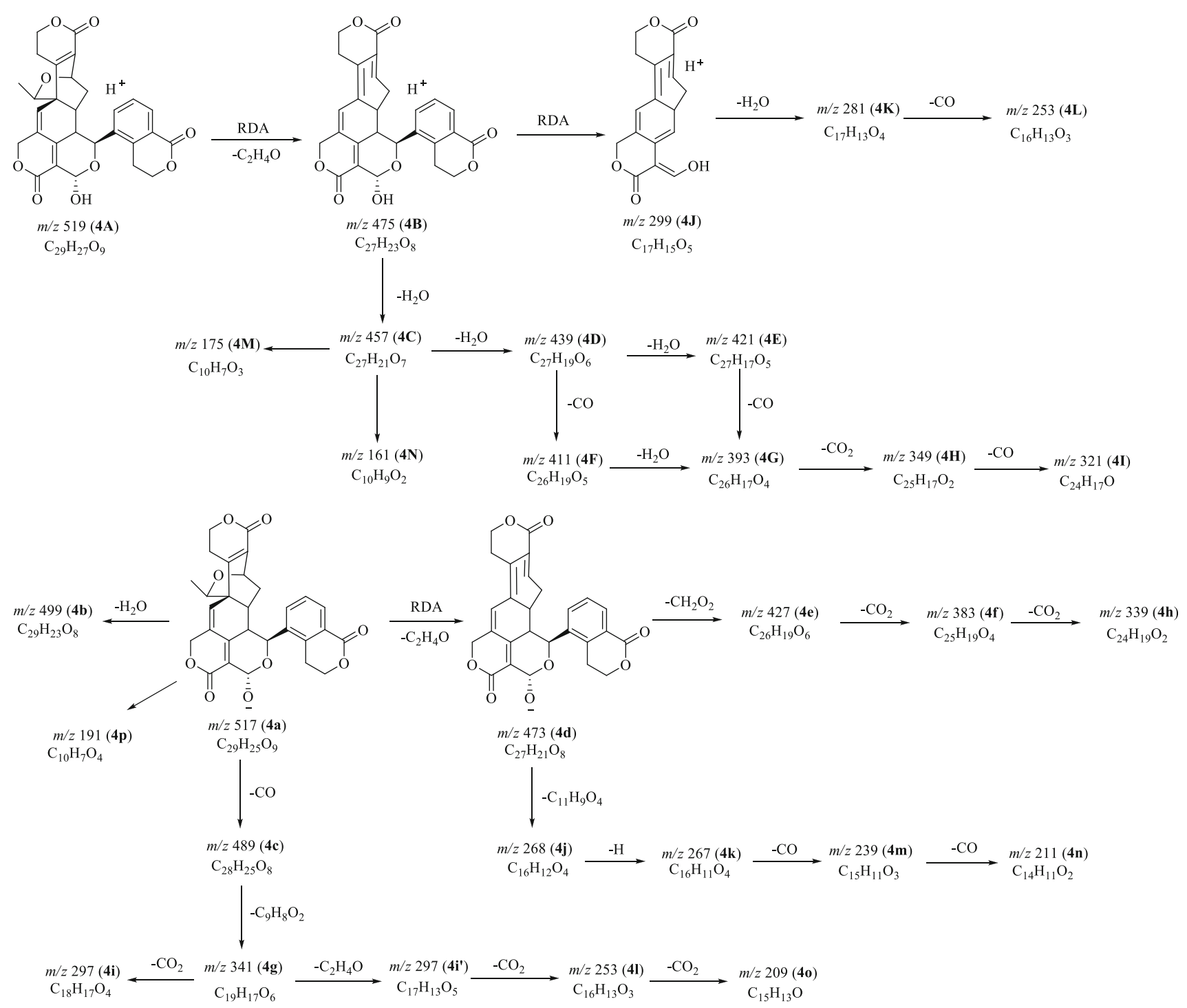

Fig. 5 Proposed fragmentation pathways of swerilactone K (4) in positive and negative modes

which was deduced as the elimination of one CO moiety from the ion 2e [18].

\subsection{ESI-IT-TOF MS ${ }^{n}$ Fragmentations of Swerilactone J \\ (3) in Positive and Negative Modes}

In the positive full-scan mass spectrum, the $[\mathrm{M}+\mathrm{H}]^{+}$ion (3A) at $\mathrm{m} / \mathrm{z} 537.1732$ was readily detected, as well as the fragment ion (3B) at $m / z 519\left(\left[\mathrm{M}+\mathrm{H}-\mathrm{H}_{2} \mathrm{O}\right]^{+}\right)$which was displayed as base peak in the subsequent $\mathrm{MS}^{2}$ experiment from 3A. The $\mathrm{MS}^{2}$ product ion at $m / z 493$ (3D) was designated as the RDA elimination of $\mathrm{C}_{2} \mathrm{H}_{4} \mathrm{O}$ moiety from $\mathbf{3 A}$ due to the presence of 1-O-ethyl group in the structure (Fig. 4). Similarly, the ion $\mathbf{3 F}(\mathrm{m} / \mathrm{z}, 475)$ was formed by losing a $\mathrm{C}_{2} \mathrm{H}_{4} \mathrm{O}$ part from 3B, and further gave rise to ions 3H $(\mathrm{m} / \mathrm{z}, 447)$ and $\mathbf{3 J}(\mathrm{m} / \mathrm{z}, 403)$ via consecutive elimination of one $\mathrm{CO}$ and one $\mathrm{CO}_{2}$ molecule [20]. The loss of a
$\mathrm{C}_{2} \mathrm{H}_{2} \mathrm{O}$ segment was characteristic, by which the fragments 3E $(\mathrm{m} / \mathrm{z}, 477), \mathbf{3 I}(\mathrm{m} / \mathrm{z}, 433)$ and $\mathbf{3 L}(\mathrm{m} / \mathrm{z}, 361)$ were formed from their respective parent ions $\mathbf{3 B}, \mathbf{3 F}$ and $\mathbf{3 J}$. In the $\mathrm{MS}^{3}$ spectrum from $\mathbf{3 B}$, the ion $\mathbf{3 C}(\mathrm{m} / \mathrm{z}, 501)$ corresponding to the loss of a $\mathrm{H}_{2} \mathrm{O}$ molecule was observed. With the elimination of a $\mathrm{C}_{3} \mathrm{H}_{4} \mathrm{O}_{2}$ part, the ion $3 \mathrm{~K}(\mathrm{~m} / \mathrm{z}, 387)$ was produced, and further generated ions $\mathbf{3} \mathbf{M}(\mathrm{m} / \mathrm{z} 343)$ and $\mathbf{3 N}(\mathrm{m} /$ $z$ 315) by successive losses of $\mathrm{CO}_{2}$ and $\mathrm{CO}$ molecules. The ion $30(\mathrm{~m} / \mathrm{z}, 307)$ in the $\mathrm{MS}^{3}$ spectrum was correspondent to the elimination of $\mathrm{C}_{6} \mathrm{H}_{6} \mathrm{O}_{3}$ moiety from precursor $3 \mathbf{I}$.

The $\mathrm{MS}^{n}$ investigation on swerilactone $\mathrm{J}(3)$ in negative mode provided more valuable information than that in positive mode. The first-stage mass spectrum displayed the $[\mathrm{M}-\mathrm{H}]^{-}$ion at $\mathrm{m} / \mathrm{z}, 535.1602$, assigned to the molecular formula $\mathrm{C}_{29} \mathrm{H}_{28} \mathrm{O}_{10}$. It should be noted that two fragmentation ions at $\mathrm{m} / \mathrm{z} 491(\mathbf{3 b})$ and $\mathrm{m} / \mathrm{z} 341\left(\mathbf{3} \mathbf{j}^{\prime \prime}\right)$ were readily obtained with high abundance in addition to the $[\mathrm{M}-\mathrm{H}]^{-}$ 
ion, assigned to the molecular formula $\mathrm{C}_{28} \mathrm{H}_{27} \mathrm{O}_{8}$ and $\mathrm{C}_{19} \mathrm{H}_{17} \mathrm{O}_{6}$, respectively. The ion $\mathbf{3 b}$ was explained by the neutral loss of $\mathrm{CO}_{2}$ from the precursor ion $\mathbf{3} \mathbf{a}$, and further confirmed by $\mathrm{MS}^{2}$ analysis in which the ion at $\mathrm{m} / \mathrm{z} 491$ was obtained as base peak. The ion $\mathbf{3 j}^{\prime \prime}\left(\mathrm{C}_{19} \mathrm{H}_{17} \mathrm{O}_{6}\right)$ was proposed to be derived from $3 \mathbf{a}$ by neutral loss of a $\mathrm{C}_{10} \mathrm{H}_{10} \mathrm{O}_{4}$ part, due to the RDA cleavage of ring F [20]. When ion $\mathbf{3 b}$ $(\mathrm{m} / \mathrm{z}, 491)$ was selected as the precursor ion to perform $\mathbf{M S}^{2}$ experiment, prolific fragment ions were obtained, from which their fragmentation rules were proposed as shown in Fig. 4. Due to the high abundance of ion $\mathbf{3} \mathbf{j}^{\prime \prime}(\mathrm{m} / z, 341.1030$, $\left.\mathrm{C}_{19} \mathrm{H}_{17} \mathrm{O}_{6}\right)$ in the first-stage mass spectrum, subsequent $\mathrm{MS}^{2-4}$ experiments were applied on ion $\mathbf{3} \mathbf{j}^{\prime \prime}$, from which a parallel fragmentation pathway was recognized. The neutral loss of $\mathrm{CO}_{2}$ from $\mathbf{3} \mathbf{j}^{\prime \prime}$ provided ion $\mathbf{3} \mathbf{m}^{\prime}(\mathrm{m} / z$ 297.1081), and further produced ions $\mathbf{3 n}(\mathrm{m} / \mathrm{z}, 279)$ and $\mathbf{3 o}(\mathrm{m} / \mathrm{z}, 253)$ through the elimination of $\mathrm{H}_{2} \mathrm{O}$ or $\mathrm{C}_{2} \mathrm{H}_{4} \mathrm{O}$ part. In the $\mathrm{MS}^{4}$ experiment from the precursor ion $3 \mathbf{n}(\mathrm{m} / \mathrm{z}, 279)$, characteristic product ions at $\mathrm{m} / \mathrm{z} 235,220$ and 193 were obtained, of which the ion at $\mathrm{m} / \mathrm{z} 235$ was consist of two closed peaks at $m / z 235.1087\left(\mathrm{C}_{17} \mathrm{H}_{15} \mathrm{O}, 3 \mathbf{3}\right)$ and $235.0749\left(\mathrm{C}_{16} \mathrm{H}_{11} \mathrm{O}_{2}\right.$, $3 \mathbf{p}^{\prime}$ ), attributed to the neutral losses of $\mathrm{CO}_{2}$ or $\mathrm{C}_{2} \mathrm{H}_{4} \mathrm{O}$ moiety from $\mathbf{3 n}$.

\subsection{ESI-IT-TOF MS ${ }^{n}$ Fragmentations of Swerilactone K (4) in Positive and Negative Modes}

Structurally, swerilactone $\mathrm{K}(\mathbf{4})$ with an aromatic ring is obviously different from swerilactones $\mathrm{H}-\mathrm{J}$ (1-3). The first-stage mass spectrum in positive mode displayed $[\mathrm{M}+\mathrm{H}]^{+}$ion $(\mathbf{4 A})$ at $\mathrm{m} / \mathrm{z} 519.1651$, corresponding to the molecular formula $\mathrm{C}_{29} \mathrm{H}_{26} \mathrm{O}_{9}$. The subsequent $\mathrm{MS}^{2}$ experiment from 4A yielded two high-abundance ions $4 \mathrm{~B}$ $(\mathrm{m} / \mathrm{z} 475)$ and $\mathbf{4 C}(\mathrm{m} / \mathrm{z} 457$, base peak), attributed to the successive losses of $\mathrm{C}_{2} \mathrm{H}_{4} \mathrm{O}$ and $\mathrm{H}_{2} \mathrm{O}$ parts, in combination with three minor ions at $\mathrm{m} / \mathrm{z} 299(\mathbf{4 J}), 281(\mathbf{4 k})$ and $253(\mathbf{4} \mathbf{L})$. The ion $\mathbf{4 J}$ was interpreted by the neutral loss of $\mathrm{C}_{10} \mathrm{H}_{8} \mathrm{O}_{3}$ from the precursor $4 \mathrm{~B}$ due to the RDA cleavage of ring $\mathbf{F}$, and further gave rise to ions $4 \mathbf{K}(\mathrm{m} / \mathrm{z}$ 281) and $\mathbf{4} \mathbf{L}(\mathrm{m} / z, 253)$ by the elimination of a molecule of $\mathrm{H}_{2} \mathrm{O}$ and $\mathrm{CO}$ (Fig. 5). This deduction was also confirmed by the $\mathrm{MS}^{3}$ analysis from the parent ion $\mathbf{4 B}$. When ion $4 \mathbf{C}\left(\mathrm{m} / \mathrm{z}\right.$ 457) was applied for the $\mathrm{MS}^{4}$ experiment, the most intensive ion at $\mathrm{m} / \mathrm{z} 439$ (4D) was readily detected, ascribe to the loss of $\mathrm{H}_{2} \mathrm{O}$, together with a series of fragment ions $\mathbf{4 E}-\mathbf{4 I}$.

In the negative ion mode, sweilactone $\mathrm{K}(\mathbf{4})$ gives rise to the deprotonated ion at $\mathrm{m} / \mathrm{z}$ 517.1511, correlated to the molecular formula $\mathrm{C}_{29} \mathrm{H}_{26} \mathrm{O}_{9}$. The following $\mathrm{MS}^{2}$ experiment on 4a provided versatile fragments with ion at $\mathrm{m} / \mathrm{z}$ $473(\mathbf{4 d})$ as base peak which was further applied for $\mathrm{MS}^{3}$ spectrum. Based on the above experiments, the fragmentation rules for swerilactone $\mathrm{K}(4)$ in negative mode were concluded. The minor ions at $\mathrm{m} / \mathrm{z}, 499(\mathbf{4 b})$ and $489(\mathbf{4 c})$ in $\mathrm{MS}^{2}$ spectrum were derived from neutral loss of $\mathrm{H}_{2} \mathrm{O}$ and $\mathrm{CO}$ from the precursor $\mathbf{4 a}$. The most abundant ion $\mathbf{4 d}(\mathrm{m} / \mathrm{z}$ 473) generated from $\mathbf{4 a}$ by the RDA elimination of $\mathrm{C}_{2} \mathrm{H}_{4} \mathrm{O}$ segment, can further give rise to ions at $\mathrm{m} / \mathrm{z}, 427$ (4e), 383 (3f) and 339 (4h) by sequential losses of $\mathrm{CH}_{2} \mathrm{O}_{2}, \mathrm{CO}_{2}$ and $\mathrm{CO}_{2}$ parts. In the $\mathrm{MS}^{3}$ spectrum from $4 \mathbf{d}$, the product ions $\mathbf{4 j}$ ( $\mathrm{m} / \mathrm{z} 268), \mathbf{4 k}(\mathrm{m} / \mathrm{z} 267), \mathbf{4 m}(\mathrm{m} / z$ 239) and $\mathbf{4 n}(\mathrm{m} / \mathrm{z} 211)$ could be explained by the consecutive elimination of $\mathrm{C}_{11} \mathrm{H}_{9} \mathrm{O}_{4}$ radical, hydrogen radical, $\mathrm{CO}$ and $\mathrm{CO}$, respectively.

\section{Conclusion}

The ESI multistage product ion mass spectra $\left(\mathrm{MS}^{n}\right)$ of swerilactones $\mathrm{H}-\mathrm{K}$ were obtained for the first time by LCMS-IT-TOF, from which their fragmentation pathways were deduced. This investigation suggested that these molecules were unstable in this $\mathrm{MS}^{n}$ study, especially for swerilactone I. The losses of $\mathrm{H}_{2} \mathrm{O}, \mathrm{CO}_{2}, \mathrm{CO}$ and $\mathrm{C}_{2} \mathrm{H}_{4} \mathrm{O}$ moieties were the particular elimination from the precursor ions due to the presence of hydroxyl, $\delta$-lactone and 1-Oethyl groups. In particular, the RDA dissociation was the most common fragmentation rule which might correspond to the fused six-membered rings in their structures. It is important to note that the loss of $\mathrm{CO}_{2}$ and $\mathrm{C}_{2} \mathrm{H}_{4} \mathrm{O}$ can be unambiguously distinguished by high-resolution mass spectrometry. Structurally, swerilactones $\mathrm{H}-\mathrm{K}$ share a closely related skeleton with the main difference located at rings $\mathrm{F}, \mathrm{G}$ and $\mathrm{H}$. Therefore, the conservative moiety (rings A to E) leads to the common fragments at $m / z 341$ and 291 in negative mode, which can be considered as the diagnostic ions for secoiridoid trimers. The present $\mathrm{MS}^{n}$ fragmentation study on swerilactones H-K (1-4) by ESI-ITTOF mass spectrometer will provide valuable information not only for their fast characterization from complicated natural mixtures but also for a better understanding of their structural architectures.

Acknowledgements This study was financed by the Youth Innovation Promotion Association (CAS), the West Light Foundation of CAS (Western Youth Scholars "A"), the Hundred Talents Program of CAS, and the Program of Yunling Scholarship.

\section{Compliance with Ethical Standards}

Conflict of interest The authors declare no conflict of interest.

Open Access This article is distributed under the terms of the Creative Commons Attribution 4.0 International License (http:// creativecommons.org/licenses/by/4.0/), which permits unrestricted use, distribution, and reproduction in any medium, provided you give appropriate credit to the original author(s) and the source, provide a link to the Creative Commons license, and indicate if changes were made. 


\section{References}

1. C.A. Geng, L.J. Wang, X.M. Zhang, Y.B. Ma, X.Y. Huang, J. Luo, R.H. Guo, J. Zhou, Y. Shen, A.X. Zuo, Z.Y. Jiang, J.J. Chen, Chem. Eur. J. 17, 3893-3901 (2011)

2. R.A. Hill, A. Sutherland, Nat. Prod. Rep. 28, 1031-1034 (2011)

3. C.A. Geng, X.M. Zhang, Y.B. Ma, J. Luo, J.J. Chen, J. Nat. Prod. 74, 1822-1825 (2011)

4. G.Z. Xin, J.L. Zhou, L.W. Qi, P. Li, Comb. Chem. High Throughput Screen 14, 93-103 (2011)

5. L. Hoffer, J.P. Renaud, D. Horvath, Comb. Chem. High Throughput Screen 14, 500-520 (2011)

6. M. Zhou, H. Luo, Z. Li, F. Wu, C. Huang, Z. Ding, R. Li, Comb. Chem. High Throughput Screen 15, 306-315 (2012)

7. L. Tokes, G. Jones, C. Djerassi, J. Am. Chem. Soc. 90, 5465-5477 (1968)

8. G.C. Kearney, P.J. Gates, P.F. Leadlay, J. Staunton, R. Jones, Rapid Commun. Mass Spectrom. 13, 1650-1656 (1999)

9. Q.R. Li, G.Q. Yan, T.F. Ge, Rapid Commun. Mass Spectrom. 21, 2843-2852 (2007)

10. R. Li, Z.J. Wu, F. Zhang, L.S. Ding, Rapid Commun. Mass Spectrom. 20, 157-170 (2006)

11. Q.R. Li, G.Q. Yan, T.F. Ge, Rapid Commun. Mass Spectrom. 22, 373-378 (2008)

12. Á. Peralbo-Molina, F. Priego-Capote, M.D. Luque de Castro, J. Agric. Food Chem. 60, 11542-11550 (2012)

13. K. Tóth, L. Nagy, A. Mándi, Á. Kuki, M. Mézes, M. Zsuga, S. Kéki, Rapid Commun. Mass Spectrom. 27, 553-559 (2013)
14. K. Ablajan, A. Tuoheti, Rapid Commun. Mass Spectrom. 27, 451-460 (2013)

15. C.A. Geng, Y.B. Ma, X.M. Zhang, S.Y. Yao, D.Q. Xue, R.P. Zhang, J.J. Chen, J. Agric. Food Chem. 60, 8197-8202 (2012)

16. B. Wang, W.Y. Chu, Z. Li, J.Q. Hou, S.L. Huang, T.M. Ou, J.H. Tan, L.K. An, D. Li, L.Q. Gu, Z.S. Huang, Rapid Commun. Mass Spectrom. 24, 2781-2786 (2010)

17. S.I. Kawano, Rapid Commun. Mass Spectrom. 23, 907-914 (2009)

18. J. Bolleddula, W. Fitch, S.K. Vareed, M.G. Nair, Rapid Commun. Mass Spectrom. 26, 1277-1290 (2012)

19. E.K. Jeong, S.Y. Lee, S.M. Yu, N.H. Park, H.S. Lee, Y.H. Yim, G.S. Hwang, C. Cheong, J.H. Jung, J. Hong, Rapid Commun. Mass Spectrom. 26, 1661-1674 (2012)

20. J. Ye, J.J. Qin, J. Su, S. Lin, Y. Huang, H.Z. Jin, W.D. Zhang, Rapid Commun. Mass Spectrom. 27, 2159-2169 (2013)

21. P.C. Eklund, M.J. Backman, L.A. Kronberg, A.I. Smeds, R.E. Sjöholm, J. Mass Spectrom. 43, 97-107 (2008)

22. Y.X. Zhang, Q.Y. Li, L.L. Yan, Y. Shi, Rapid Commun. Mass Spectrom. 25, 2173-2186 (2011)

23. A.D. Lucas, J. Fernandez-Gadea, N. Martin, R. Martinez, C. Seoane, Rapid Commun. Mass Spectrom. 14, 1783-1786 (2000)

24. J.J.J. van der Hooft, J. Vervoort, R.J. Bino, J. Beekwilder, R.C.H. de Vos, Anal. Chem. 83, 409-416 (2011)

25. W. Ding, K. Liu, X.J. Liu, H.X. Luan, C.F. Lv, T. Yu, G.M. Qu, J. Appl. Polym. Sci. 129, 2057-2062 (2013)

26. E.M. Thurman, J. Mass Spectrom. 41, 1287-1297 (2006) 